\title{
Using High-Resolution Imagery Acquired with an Autonomous Unmanned Aerial Vehicle for Urban Construction and Planning
}

\author{
Lei Ma* \\ Department of Geographical Information Science, Nanjing \\ University, Nanjing, China \\ malei0526@qq.com \\ Yafei Wang \\ Department of Geographical Information Science, Nanjing \\ University, Nanjing, China \\ Liang Cheng* \\ Department of Geographical Information Science, Nanjing \\ University, Nanjing, China \\ lcheng@nju.edu.cn
}

\author{
Manchun Li * \\ Department of Geographical Information Science, Nanjing \\ University, Nanjing, China \\ manchun@nju.edu.cn \\ Lihua Tong
}

Department of Geographical Information Science, Nanjing University, Nanjing, China

\begin{abstract}
In developing country, most of cities are expanding rapidly, and many projects of infrastructure construction are implementing. Hence, the remits of regional planning and monitoring are growing steadily. Planning data and status information need to made available in ever more up-to-date form and with high spatial resolution. Given the constraints on public funding and technique, real-time and high spatial resolution data is difficult to acquire with a user-defined frequency. However, Unmanned Aerial Vehicles (UAVs) technology provides potential for very high spatial resolution $(<25 \mathrm{~cm})$ mapping of relatively large areas at a user-defined re-survey frequency. According to our experience, in this paper, we would propose some application about UAVs for urban managers, to (a) serve city lay-out, (b) guide the development demolition, (b) realize dynamic monitoring, (c) calculate the percentage of greenery coverage, (d) construct three-dimensional city model, and so on. These projects and experiences proved that UAVs technology is feasible for Urban Construction and Planning.
\end{abstract}

Index Terms-Unmanned Aerial Vehicles (UAVs), HighResolution, Urban Construction, Planning, Development demolition.

\section{INTRODUCTION}

With social and economic development in city, traditional two dimension data can't fulfill the routine work for each department, because it is pressed for more comprehensive image data. However, remote sensing image have become an important part of based geography spatial data framework of city, for its abundant information content, rapid collecting, and so on. The utility of remote sensing as a tool for monitoring the senescence and change of city has long been recognized. UAVs technology, with its flexible flight activation time and re-flight capability, provides an ideal tool to map and monitor the change in city land cover. It can be used for urban construction, transforming the appearance of a city, planning the river, and so on.

With the recent developments of low-cost sensors such as consumer digital cameras, GPS/INS (Global Positioning System / Inertial Navigation System), small size UAVs have reached a level of practical reliability and functionality that enables this technology to enter the geomatics market as an additional platform for spatial data acquisition [1]. At the current state mainly low-cost UAVs are used in mapping projects with low budgets. Though one could imagine a wide variety of interesting sensors to be mounted on such a device, here we will focus on photogrammetric applications using consumer digital cameras [2]. In praxis, UAVs-based photogrammetry will only be accepted when it provides the required accuracy and an additional value and it is competitive in terms of economic application compared to other measurement technologies [1]. Limited real conditions, it is still expected that with further methodological refinement and more complex methods of automated radiometric correction UAVs technology can provide the flexibility to rapidly produce very high resolution map products to aid city management.

While UAVs technology were improving constantly, research groups focused on applications using rotary and fixed wing UAVs for forest resource management and monitoring [3], vegetation monitoring [4], classification of hyperspectral UAV imagery [5], road following [6], river monitoring [7], recording of large scale urban and suburban sites [8], the mapping of archaeological sites [9], disaster management, oil and gas pipeline monitoring, laying of pipes and cables [10], 3D modeling and photorealistic texture mapping of a medieval castle [11], and investigated the accurate DSM production [12]. In recent research, Dunford et al. [13] used UAVs technology to quantify riparian terrain and vegetation units and identify standing dead wood and canopy mortality for riparian 
managers. To classifying rangeland vegetation from a fivecentimeter-resolution UAS image mosaic, Laliberte and Rango [14] developed and evaluated an image processing workflow that included the integration of resolution-appropriate field sampling, feature selection, and object-based image analysis. Precision farming was developed as a flexible and powerful tool for site-specific vineyard management [15].

It was no doubt that all of the applications had great expectations. But most of them were considered to the area where is sparsely populated. In this paper, we would propose some application about UAVs for aiding urban managers, to (a) serve city lay-out, (b) guide the development demolition, (b) realize dynamic monitoring, (c) calculate the percentage of greenery coverage, (d) construct three-dimensional city model, and so on.

\section{ACQUISITION AND PROCESSING OF UAVS IMAGERIES}

We used the fixed wing UAVs with Canon EOS 5D Mark II digital camera to acquire imagery at $80 \%$ forward lap and $60 \%$ sidelap. Imagery was acquired in August 2011 at a flying height of $750 \mathrm{~m}$ above ground over a plane landscape at the Deyang Experimental Range in Sichuan of China. The camera's resolution was $5616 \times 3744$ pixels, resulting in an image footprint of $1123 \mathrm{~m} \times 748 \mathrm{~m}$ with a pixel resolution of $0.2 \mathrm{~m}$.

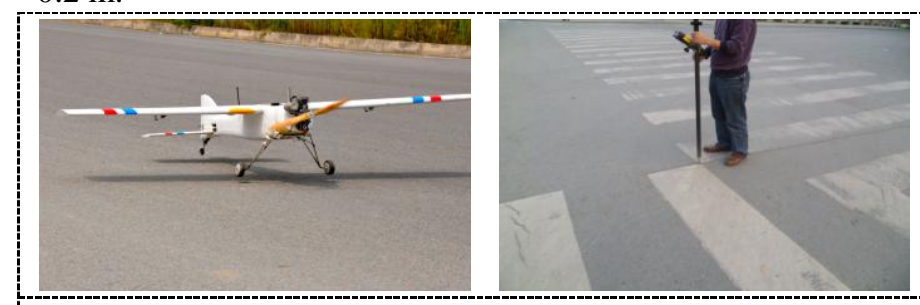

Figure 1. UAVs platform for acquiring imagery. UAV(left), Collect ground control points (GCPs) (right).

The main procedure for measurement mission is as follow:

\section{A. Data preparation:}

- Camera calibration files: measured automatically, focal length $\mathrm{c}$, the coordinates of the principal point $\mathrm{xP}, \mathrm{yP}$ and the radial lens distortion parameters were estimated within a bundle adjustment. Further parameters of lens distortion were not significant, therefore they were neglected [1].

- Imageries acquired with UAVs. The imageries with consumer camera always had large image scale, irregular overlap, strong geometric and radiometric changes.

- Position Orientation System (POS) data: with the Position Orientation System, a GPS coordinate and elevation are recorded for each image, yet the roll, pitch, and heading of the platform. However, even with the autopilot system, the plane was affected by wind and thermals, which are common in the low-altitude environment [5]. The roll, pitch, and heading of the platform were useless for imageries processing, and only the coordinate was used to depict the aerial strips.
- Ground Control points: acquired by Real-time kinematic (RTK), including the coordinates, recording of the point and the image with position of point.

\section{B. Data pre-processing:}

- Data format conversion, editing GCPs, images and camera calibration parameters for data processing software (DPGRID).

- Images distortion correction. Use camera calibration parameters to correct every imagery for further processing.

Image intensification for feature extraction and matching automatically.

- Automatic aerial triangulation (AAT). It is crucial step for image orientation, and yet more difficult for UAVs imageries.

C. Generate DEM: it is a low-accuracy DEM.

D. Orthorectification: digital differential rectification, using the DEM to correcting images.

E. Unify the imageries: adjust the colour, luminance and contrast of the imageries, to uniform the tone and balance the contrast.

F. Mosaic: merge the corrected single image together.

G. DOM editing: the resampling of the mosaic was implemented to rectify image blur, malposition, warping.

H. Mapsheet crop: output the final production corresponding scale.

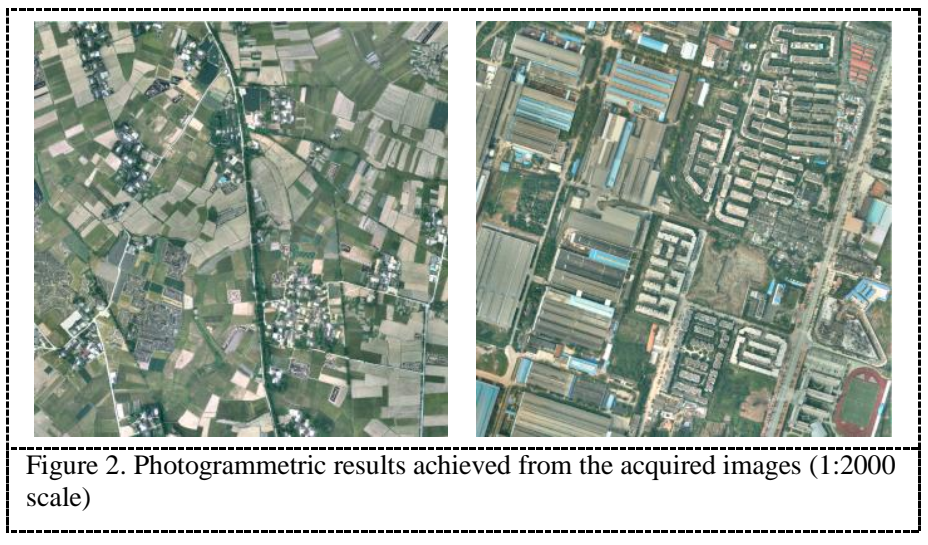

\section{APPLICATION OF UAVs IMAGERIES IN CITY}

\section{A. Guide the development demolition}

In china, most of managers for city planning were expecting to acquire detailed data about building, road and farmland at planning area, to guide the development demolition efficiently, for urban renewal and real estate development. UAVs technology provided potential for very high spatial resolution $(<25 \mathrm{~cm})$ mapping of relatively large areas at a userdefined re-survey frequency. Using Geographic Information System (GIS), the statistics for compensation in demolition 
area could be estimated detailedly. If the results could be as the law, more compensation fund would be saved.

\section{B. Construct three-dimensional city model}

Based on the low-latitude imageries from UAVs, for their rich side texture for building, automatic 3-D construction for building would be easier to implement without acquiring the texture of building out-door. On the other hand, illumination analysis, planning solution selection, limitation analysis for new building height could be realized with the 3-D city model with accuracy geometric model.

\section{Serve city lay-out}

According to our experience, the DOM from UAVs could greatly guide the earlier investigation for city planning. If adequate fixed GCPs were arranged in the city, such maps can be generated almost in real time, and would greatly facilitate urban planning activities.

\section{Realize dynamic monitoring}

Low-cost UAVs technologies provided a feasible approach for high frequency monitoring the city change especially to the buildings, to overcome limited fund and satellite round.

\section{E. Calculate the percentage of greenery coverage}

Firstly, object-oriented classification was considered to calculate the percentage of greenery coverage [16]. Although the spatial resolution is very high, the spectral and radiometric resolutions obtained from the low-cost consumer camera were relatively low, and the red (R), green $(\mathrm{G})$ and blue (B) bands are highly correlated. It was sure that presented challenges compared to using imagery from higher quality mapping cameras. Here eCognition 8 was applied to extract the green land cover.

\section{DISCUSSION AND CONCLUSION}

The article presented an overview of existing UAVs applications with particular attention to those platforms used for serving city construction. Through conducting acquisition, proceeding, application for imageries, we had already demonstrated the feasibility of such imaging missions. Undoubtedly, current UAVs systems have a great potential for many applications. But efficient geo referencing is still a key issue. To city application, the developer must understand the special requirements of photogrammetry or classification, such as very high building influence to georeferencing or how to improve the automatic classification accuracy for UAVs optical imagery. Additionally, photogrammetrists have to develop new methods for efficient geo referencing and also use the potential for direct georeferencing. Ultimately, our goal was to demonstrate a workflow consisting of acquisition, orthorectification, mosaicking, and classification of UAVs imagery suitable for city monitoring at relatively low costs with quick turnaround times.

\section{ACKNOWLEDGMENT}

This work is supported by the National Natural Science Fou ndation of China(GrantNo.41001238), the National Key Techno logy R\&D Program of China(GrantNo.2012BAH28B02), and the Scientific Research Foundation of Graduate School of Nanjing University (2013CL09).

\section{REFERENCES}

[1] M. Sauerbier, E. Siegrist, H. Eisenbeiss, and N. Demir, "The practical application of UAV-based photogrammetry under economic aspects," International Archives of the Photogrammetry, Remote Sensing and Spatial Information Sciences. Zurich: UAV-g congress, 2011.

[2] http://www.geometh.ethz.ch/research/uav. [Accessed 2012.12]

[3] A. Horcher, and R. J. M. Visser, "Unmanned aerial vehicles: applications for natural resource management and monitoring," Council on Forest Engineering Annual Meeting. Hot Springs (AR), USA, 2004.

[4] R. Sugiura, N. Noguchi, and K. Ishii, "Remote-sensing technology for vegetation monitoring using an unmanned helicopter, "Biosystems Engineering. New York: Vol. 90, pp. 369-379, April 2005.

[5] A. S. Laliberte, C. Winters, and A. Rango, "Acquisition, orthorectification, and classification of hyperspatial UAV imagery," Fourth Annual Symposium: Research Insights in Semiarid Scosystems, RISE, University of Arizona, Tucson, 2007.

[6] J. Egbert, and R. W. Beard, "Road following control constraints for low altitude miniature air vehicles," American Control Conference, New York, pp. 353-358, 2007.

[7] N. Masahiko, "UAV borne mapping system for river environment," 28th Asian Association of Remote Sensing Conference, Kuala Lumpur, 2007.

[8] S. Spatalas, V. Tsioukas, and M. Daniil, "The use of remote controlled helicopter for the recording of large scale urban and suburban sites," Culture of Representation, Xanthi, 2006.

[9] P. Patias, C. Saatsoglou-Paliadeli, O. Georgoula, M. Pateraki, A. Stamnas, and N. Kyriakou, "Photogrammetric documentation and digital representation of the macedonian palace in VerginaAegeae," CIPA, XXI International CIPA Symposium, Athens, 2007.

[10] S. Niranjan, G. Gupta, N. Sharma, M. Mangal, and V. Singh, "Initial efforts toward mission-specific imaging surveys from aerial exploring platforms: UAV," GIS development, Map World Forum, Hyderabad, 2007..

[11] H. Pueschel, M. Sauerbier, and H. Eisenbeiss, "A 3D model of Castle Landenberg $(\mathrm{CH})$ from combined photogrammetric processing of terrestrial and UAV-based images," The International Archives of the Photogrammetry, Remote Sensing and Spatial Information Sciences, Beijing: ISPRS Congress, pp. 93-98, 2008.

[12] R. B. Haarbrink, and H. Eisenbeiss, "Accurate DSM production from unmanned helicopter systems," International Archives of Photogrammetry, Remote Sensing and Spatial Information Sciences, Beijing: ISPRS Congress, pp. 1259-1264, 2008.

[13] R. Dunford, K. Michel, M. Gagnage, H. Piegay, and M. L. Tremelo, "Potential and constraints of unmanned aerial vehicle technology for the characterization of mediterranean riparian forest," International Journal of Remote Sensing, vol. 30, pp. 4915-4935, 2009.

[14] A. S. Laliberte, and A. Rango, "Image processing and classification procedures for analysis of sub-decimeter imagery 
acquired with an unmanned aircraft over arid rangelands," GIScience \& Remote Sensing, vol. 48, pp. 4-24, 2011.

[15] J. Primicerio, S. F. D. Gennaro, E. Fiorillo, L. Genesio, E. Lugato, A. Matese, and F. P. Vaccari, "A flexible unmanned aerial vehicle for precision agriculture," Precision Agriculture, vol. 13, pp. 517-523, 2012.

[16] T. Blaschke, "Object based image analysis for remote sensing," ISPRS Journal of Photogrammetry and Remote Sensing, vol. 65, pp. 2-16, 2010. 